\title{
Real-Time Monitoring \& Adaptive Protection of Power Transformer to Enhance Smart Grid Reliability
}

\author{
Maulik Raichura (Researcher, A. D. Patel Institute of Technology, Gujarat Technological University, India), \\ N. G. Chothani ${ }^{*}$ (PhD, Associate Professor, A. D. Patel Institute of Technology, \\ Gujarat Technological University, India), \\ Dharmesh Patel (PhD, Assistant Professor, Government Engineering College Bharuch, \\ Gujarat Technological University, India)
}

\begin{abstract}
Power transformer is one of the most important pieces of equipment in the grid to reliably and efficiently transmit power to the consumers. Asset management and protection are the best concepts for prolongation of transformer lifespan as well as for the increase of grid reliability. This article presents electrical and non-electrical parameter-based power transformer monitoring and protection. Various data such as core flux, age of asset, heat generation, current harmonics and temperature are monitored in real time and processed accordingly to enhance the working capability of the transformer. The proposed scheme is successfully tested on $15 \mathrm{kVA}$ laboratory transformer using Arm CORTEX-M4 processor. A Fitness Function $\left(F_{f}\right)$ is estimated from the collected data to examine the working condition of the transformer. Moreover, voltage, current and power-based inrush detection as well as Adaptive Power Differential Protection (APDP) are applied to protect the transformer against fault. The hardware implementation and result validation prove the effectiveness of the proposed scheme in enhancing reliability of the distribution grid.
\end{abstract}

Keywords - Condition monitoring; Fault detection; Power transformers; Reliability; Smart Grid.

\section{INTRODUCTION}

Keeping up with the trending development in power systems due to several benefits offered by smart grid and technology nowadays, it is required to change the criteria of protective schemes adding a self-healing feature. In order to improve the overall monitoring and protection of a transformer, it is necessary to analyse all the parameters. Considering its self-importance and complexity due to nonlinear magnetizing core characteristics with different voltage level, transformer protection proves its significance [1]. PLC based transformer cooling control system is applied by intelligent means [2]. Online condition monitoring for the distribution transformer is elaborated and discussed in [3]; however, many schemes are lacking the protection criteria in combination with conditioning monitoring. IEEE has provided guidance for assessment and reconditioning of oil immersed transformers [4], [5]. Time-based maintenance is nowadays replaced by condition-based maintenance as a part of the smart transformer to improve lifespan and reliability with the help of leakage current and partial discharge sensors [6].
Transformer asset management is widely known as the factor that conditions monitoring and controlling. Dissolved Gas Analyzer (DGA) facilitates identifying transformer conditions. A dissolved gas sensor with multiple gas measuring technique allows for better prediction of failure possibilities [7]. Fuzzy Logic (FL) based health index is calculated for the oil immersed transformer with real field data in [8]. In turn, FL based transformer asset management considering DGA, temperature, etc. is elaborated in [9]. Based on oil insulation test and FL model decision, a prediction is carried out for the remaining operational life of the transformer in [10]. Based on various uncertainty and conflict information, FL is used to evaluate transformer health conditions in [11]. Conditional monitoring-based transformer asset management greatly increases the diagnostic accuracy [12]. Transformer risk index is evaluated through asset management plan [13] with optimal physical asset management. To reduce maintenance charges, maintenance strategy is planned based on the evaluation of life cycle, equipment cost, overhauling time and repairing cost [14]. Differential current gradient vector-based technology [15] was involved in protective schemes of a transformer. Voltage and current ratio [16] based scheme is successfully integrated for inrush and fault discrimination. Power Differential Protection (PDP) [17] signals a new era for protection schemes, which successfully ensure wide area protection with large contingencies. The PDP based transmission line [18] protection is also well-known among the researchers. On the other hand, Current Differential Protection (CDP) scheme requires phase compensation [19]. Moreover, in the CDP scheme, the fundamental component of current should be extracted to measure magnitude of the current and phase angle should be extracted to measure phase difference separately [20]. So, computational complexity will increase in the CDP scheme compared to the PDP scheme. Another challenge lies in the fact that current acts as the dominant quantity in the CDP scheme while no other quantities are involved [21].

This article describes a real-time monitoring of the smart grid transformer by assessing Fitness Function $\left(F_{\mathrm{f}}\right)$. Continuous monitoring of the transformer is achieved by estimating $F_{\mathrm{f}}$ considering various parameters like current, voltage, power

\footnotetext{
* Corresponding author.

E-mail: chothani_nilesh@rediffmail.com
} 
winding temperature, harmonics, frequency, etc. Breaching the limit of $F_{\mathrm{f}}$ will lead to notifying the person at work and decision on the isolation of the asset based on the severity of limit breach. Moreover, an adaptive power differential algorithm is proposed to protect the transformer against hazardous fault events. Hardware implementation of condition monitoring and protection scheme presented here proves its efficacy in improving the performance of grid tied transformer.

\section{PROPOSED TECHNIQUE}

Fig. 1 presents a comprehensive diagram for real time condition monitoring and protection of a power transformer.

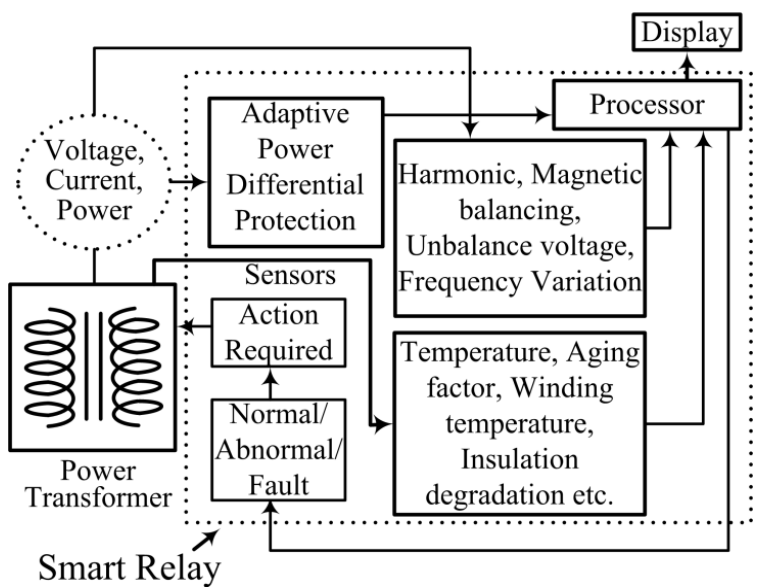

Fig. 1. Generalized schematic diagram for transformer monitoring and protection.

Various data are collected through data logger to display the collected data and record them for future analysis. The suggested scheme is tested on hardware using the CORTEX M4 processor available in the laboratory. If the violation of any considered parameters occurs with respect to the predefined limit, then the estimated $F_{\mathrm{f}}$ provides information to the monitoring and protective scheme. With the help of such information, preventive action is carried out to retain the transformer in service for a longer time. Along with monitoring, an Adaptive Power Differential Protection (APDP) scheme is also proposed, which will take care of the transformer against internal faults. Both online monitoring and adaptive power differential protection techniques are executed simultaneously in the hardware processor to enhance reliability of the transformer in the smart grid.

\section{A. Condition Monitoring of the Transformer}

Condition monitoring of the transformer is performed by taking certain parameters into consideration [3]. We have considered selected parameters like Magnetic Unbalance (MUB), Winding Temperature (WT), aging factor, insulation degradation [22], current harmonics, winding deformation, and heat generation (total). After acquiring the real-time data, the actual values of the said parameters are estimated in the CORTEX M4 processor using a set of equations [3].

Later, a fitness function $\left(F_{\mathrm{f}}\right)$ is defined duly considering all effect, as

$$
F_{\mathrm{f}}=\frac{1}{S_{\max }} \cdot \frac{\sum_{i=1}^{j} S_{i} \cdot W f_{i}}{\sum_{i=1}^{j} W f_{i}} .
$$

Where, $j$ is the number of parameters, $S_{i}$ is the score of parameters; $S_{\max }$ is the maximum score of the parameter and $W f_{i}$ is the weight factor of each parameter. Here, different parameters have different values and units, hence the score is defined here as an index assigned for a particular range of values, e.g. oil level is expressed as percentage and winding temperature is measured in Celsius scale. Also, the weight factor is assigned based on the dominancy of the parameter, i.e. the change in the parameter that highly affects the transformer is assigned ' 1 ' weight factor and consecutively in the decreasing order up to ' 4 '. One can change the assigned weight factor $\left(W f_{i}\right)$ and score $\left(S_{i}\right)$ based on their requirements for monitoring the transformer. Table I shows the score and weight factors for the considered parameters, which were acquired for the real time test setup.

TABLE I

PARAMETERS AND RESPECTIVE WEIGHT FACTORS FOR DEFINED FITNESS FUNCTION

\begin{tabular}{|c|c|c|c|c|c|c|}
\hline \multirow{2}{*}{$\begin{array}{l}\text { Sr. } \\
\text { No. }\end{array}$} & \multirow{2}{*}{$\begin{array}{l}\text { Parameters } \\
\text { Considered }\end{array}$} & \multicolumn{4}{|c|}{ Score $\left(S_{i}\right)$} & \multirow{2}{*}{$W f_{i}$} \\
\hline & & 4 & 3 & 2 & 1 & \\
\hline 1 & MUB & $0-0.2$ & $0.21-0.4$ & $\begin{array}{c}0.41- \\
0.6\end{array}$ & $>0.6$ & 3 \\
\hline 2 & WT & $65-70$ & $71-80$ & $81-90$ & $>90$ & 1 \\
\hline 3 & Aging Factor & $0.1-0.2$ & $0.21-0.3$ & $\begin{array}{c}0.31- \\
0.4\end{array}$ & $>0.4$ & 4 \\
\hline 4 & $\begin{array}{c}\text { Insulation } \\
\text { Degradation }\end{array}$ & $0-0.2$ & $0.21-0.4$ & $\begin{array}{c}0.41- \\
0.6\end{array}$ & $>0.6$ & 2 \\
\hline 5 & $\begin{array}{c}\text { Current } \\
\text { Harmonics } \\
(\% \text { THD }) \\
\end{array}$ & $0-5$ & $6-20$ & $21-40$ & $>40$ & 2 \\
\hline 6 & $\begin{array}{c}\text { Winding } \\
\text { Deformation }\end{array}$ & $\begin{array}{c}0.0005- \\
0.005 \\
\end{array}$ & $\begin{array}{c}0.0051- \\
0.05 \\
\end{array}$ & $\begin{array}{c}0.051- \\
0.1 \\
\end{array}$ & $>0.1$ & 3 \\
\hline 7 & $\begin{array}{l}\text { Total Heat } \\
\text { Generation }\end{array}$ & $65-70$ & $71-80$ & $81-90$ & $>90$ & 1 \\
\hline
\end{tabular}

\section{B. Transformer Protection Approach}

Protection of the transformer is critically important for the reliability of supply and healthy operation of the power system. Here, real-time monitoring in conjunction with protection of the transformer is proposed to enhance continuity of supply in the grid. The acquired parameters used for monitoring are considered for protection. Hence, it provides for the economical operation by eliminating the cost of extra peripheral devices.

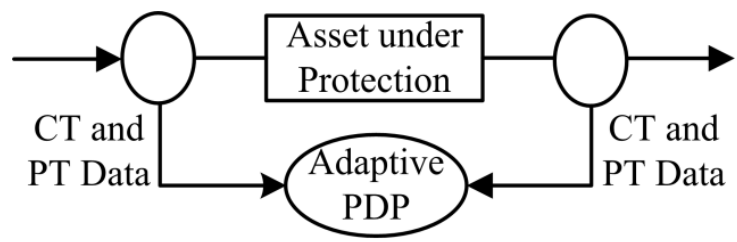

Fig. 2. Proposed Adaptive Power Differential Protection (APDP) scheme

In this article, an Adaptive Power Differential Protection (APDP) for the transformer considering CT saturation is proposed, as shown in Fig. 2. The scheme presented here is to some extent similar to that of the Current Differential Protection 
(CDP). However, this scheme offers advantages of adaptive characteristics and reliable operation as compared to the CDP. The proposed APDP scheme is based on the calculation of the average power of all three phases on both sides of the transformer. This does not require estimation of the fundamental current/voltage magnitude and angles as required in the CDP scheme, phase wise. Moreover, the computational steps and summation logics are also reduced in the APDP scheme. Here, the input power should be the summation of the output power and losses that occurred in the transformer. If the difference between the powers measured at both ends exceeds the settled threshold, then it is interpreted as an internal fault in the asset and the relay will issue a trip signal.

In addition, a novel logic of "Voltage Equality" is proposed, which can effectively identify the existence of a fault at the time of inrush condition (transformer energization). The Power Transformer (PT) ratio of both sides of the transformer is taken so that it gives the same output voltage despite of any transformation ratio. It is observed that at the time of inrush condition, voltages acquired at both sides of the PTs are the same, i.e. $V_{\mathrm{p}}=V_{\mathrm{s}}$. This is because at the instant when the primary is energized (under healthy condition), the secondary of the transformer reflects the desired voltage.

On the other hand, in case of fault prior to the transformer energization, output of both sides of PT will not be equal, i.e. $V_{\mathrm{p}} \neq V_{\mathrm{s}}$ and hence there may be persistence of fault during inrush condition. In the processor, a comparator (logic) is used to compare the primary and secondary side PT voltages for identification of inrush or fault during inrush.

Further discrimination of internal and external fault is carried out by percentage biased adaptive power differential characteristic. As shown in Fig. 3, the characteristic is drawn between differential power $\left(P_{\mathrm{d}}\right)$ and restraining power $\left(P_{\mathrm{r}}\right)$ which is the average power $\left(\left(P_{1}+P_{2}\right) / 2\right)$, where $P_{1}$ is the primary side power and $P_{2}$ is the secondary side power of the transformer.

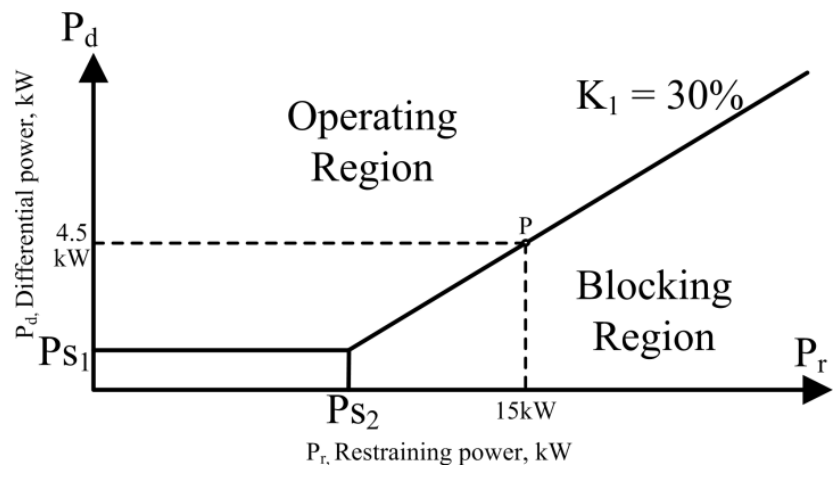

Fig. 3. Differential power $V_{\mathrm{s}}$ restraining power characteristic.

With respect to the specifications of the transformer, $30 \%$ slope $\left(K_{1}\right)$ is considered as biased setting for relay operating criteria. Hence, if the differential power exceeds $30 \%$ of the restraining power (average, in this case), the proposed scheme considers this situation as an internal fault in the transformer.

For the case of an internal fault condition (Fig. 3):

(1) When $P_{\mathrm{r}}<P_{\mathrm{S} 2}$ and if $P_{\mathrm{d}}>P_{\mathrm{S} 1}$, then relay will operate.
(2) When $P_{\mathrm{r}}>P_{\mathrm{S} 2}$ and if $P_{\mathrm{d}}>P_{\mathrm{S} 1}+K_{1} \cdot P_{\mathrm{r}}$, then relay will operate.

Where $K_{1}$ is the initial slope set in the adaptive relay algorithm. $P_{\mathrm{S} 1}$ is the basic differential power setting and $P_{\mathrm{S} 2}$ is the biased power threshold setting.

During severe fault condition, Current Transformers (CTs) may get saturated [24]. If CTs get saturated during external fault, then a simple Power Differential Protection (PDP) based scheme may mal-operate. To prevent these types of undesired activities, the PDP scheme is refurbished by adding an adaptive feature. This adaptive characteristic will prevent false tripping during external fault with the CT saturation. The author has also developed adaptive fault impedance compensation algorithm for the transmission line [23]
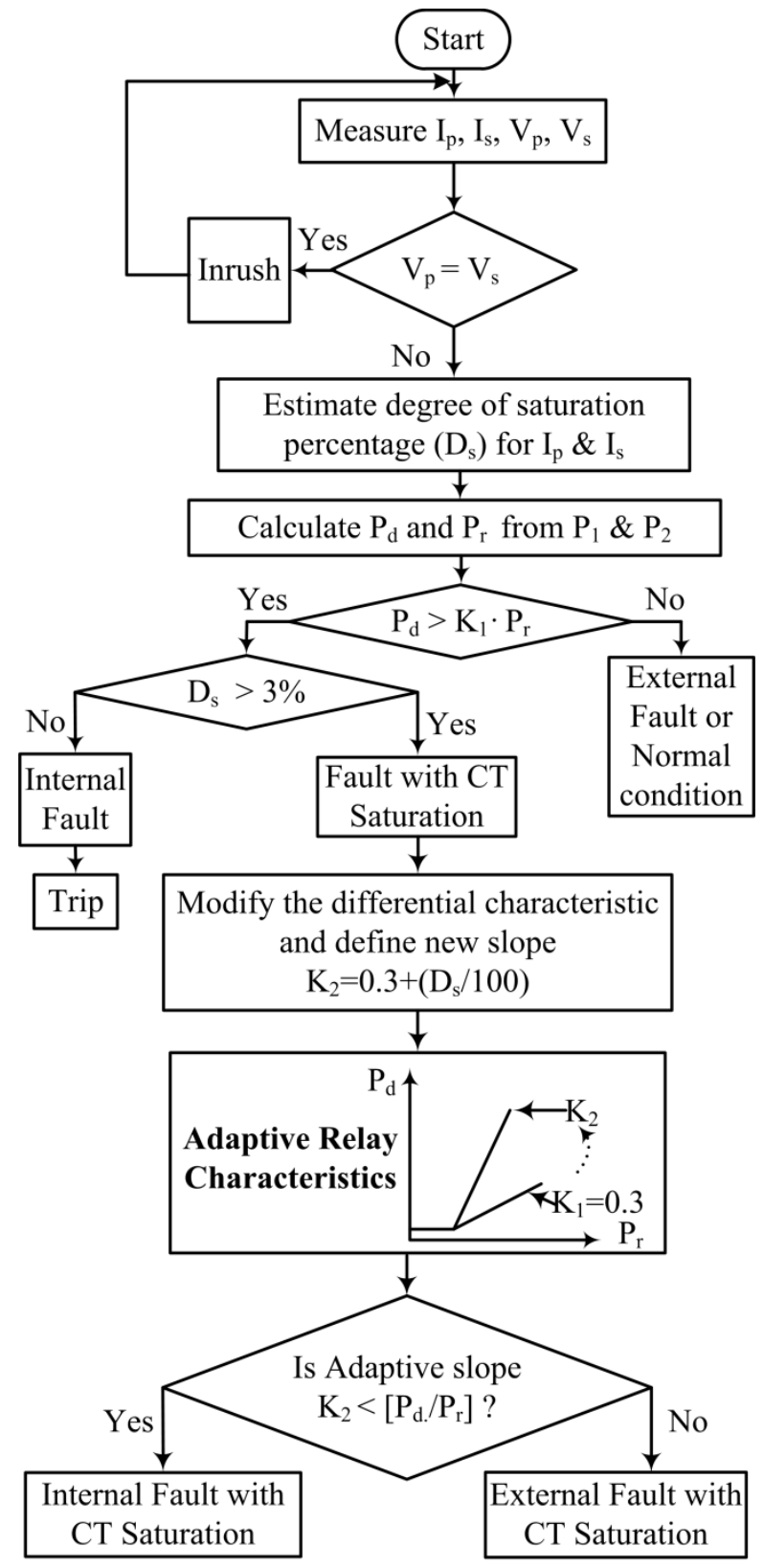

Fig. 4. Proposed adaptive PDP based algorithm. 
Fig. 4 presents the flowchart for the APDP scheme proposed for transformer protection. Initially, currents and voltages of both sides of the transformer are measured with the help of CTs and PTs (same measuring equipment is used for condition monitoring of the transformer). As described above, to discriminate the internal fault and inrush condition at the time of energization, the voltage equality test is performed. If voltages of both sides of the transformer $\left(V_{\mathrm{p}} \& V_{\mathrm{s}}\right)$ are not equal, then it is considered as the presence of fault and the algorithm further checks for the type of fault, conversely, if voltages are equal, then it is the case is of inrush condition.

Further, if the fault condition is detected, the degree of saturation $\left(D_{\mathrm{s}}\right)$ of both sides current $\left(I_{\mathrm{p}} \& I_{\mathrm{s}}\right)$ is measured from equation (2), which is given below:

$$
D_{\mathrm{s}}=1-\frac{\text { Saturated Current }}{\text { Unsaturated Current }} \cdot 100 \% \text {, }
$$

where $D_{\mathrm{s}}=$ degree of saturation.

After that, differential power $\left(P_{\mathrm{d}}\right)$ and restraining power $\left(P_{\mathrm{r}}\right)$ are estimated using computational method in the processor. Digital multiplication of voltage and current samples, acquired from power logger (equipped with A/D converter) is used [25].

If $P_{\mathrm{d}}$ remains less than $P_{\mathrm{r}}$, then the condition is of external fault or normal. But if $P_{\mathrm{d}}$ exceeds $P_{\mathrm{r}}$, then it may indicate the presence of internal fault or external fault with CT saturation. Further, if the degree of saturation remains below $3 \%$ and already $P_{\mathrm{d}}$ exceeded $P_{\mathrm{r}}$, then it can be understood that it is the case of internal fault condition and trip signal will be immediately issued to the Circuit Breaker (CB). On the other hand, if the degree of saturation of the currents exceeds $3 \%$, then it can be understood as the presence of fault, which should be discriminated properly to prevent false tripping from external fault condition (Fig. 4).

As the saturation level grows higher, the necessary action is to be taken to shift the characteristic from lower slope to higher adaptively, otherwise the relay will issue a false trip signal. So, the algorithm will now calculate the new slope $\left(K_{2}\right)$ of power differential characteristic with the help of Equation (2), as given in Eq. (3).

New slope is defined as

$$
K_{2}=0.3+\frac{D_{\mathrm{s}}}{100}
$$

Here, $K_{2}$ is the new slope for the APDP scheme.

Analysing further to identify whether the fault is internal or external, the algorithm will again check whether the adaptive slope is less than the ratio of differential power to restraining power. If the new slope is lower than the ratio $\left(P_{\mathrm{d}} / P_{\mathrm{r}}\right)$, then it can be concluded that the fault is internal with $C T$ saturation and trip signal should be generated, otherwise it is decided that external fault with CT saturation occurred (the scheme remains inoperative).

\section{EXPERIMENTAL TEST SETUP AND DISCUSSION OF RESULTS}

Hardware setup is developed in the laboratory to authenticate the proposed real-time monitoring and adaptive power differential protection scheme for the transformer. The snapshot of the developed hardware setup is shown in Fig. 5. The transformer considered is a three-phase, $15 \mathrm{kVA}, 440 / 220 \mathrm{~V}$, $50 \mathrm{~Hz}$ rated having multiple tapings on both sides. Also, rheostats and inductors are placed before and after the transformer to replicate the effect of transmission line, which is present in the real time conditions. Transformer's primary side is connected with 3-phase, $440-\mathrm{V}$ separate generator and the secondary side is connected to 3-phase 220-V electricity board supply through auto transformer to perfectly create the internal fault scenario, which takes place in practice. The CTs are connected to the primary and secondary side with appropriate ampere rating. Primary side and secondary side internal faults are generated by connecting $12 \mathrm{~A}, 18 \Omega$ variable resistors. Additional $250 \Omega$ rheostat is inserted in the secondary side of the CTs to create saturation effect during internal and external fault conditions. High resolution DSO and power logger are utilized in the hardware to observe and record the current and voltage data during each abnormal condition.

Various inrush, internal fault and external fault conditions with spectrum analysis and harmonic analysis are carried out considering the practical aspects. Only selected results are presented here due to space limitations.

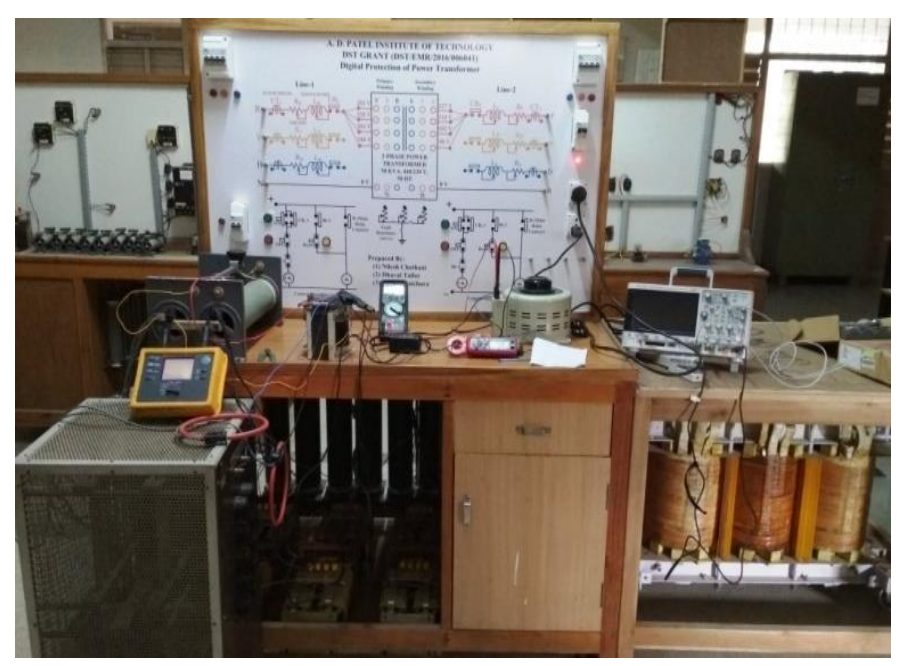

Fig. 5. Developed laboratory setup

\section{A. Inrush Condition}

At the time of transformer energization, voltage equality test will be carried out using the algorithm (Fig. 4). As shown in Fig. 6(a), when the transformer is switched on from the primary side (closing of CB) at 0.2 second, voltages of the primary and secondary side of the transformer are equal $\left(V_{\mathrm{p}}=V_{\mathrm{s}}\right)$ and follow the same waveform pattern as measured from the PT secondary. Moreover, the calculated RMS values in the processor of these voltages are equal, which is shown in Fig. 6(b). The proposed algorithm recognizes this condition as inrush (healthy energization of the unit) and returns back to fetch the next sample. 



Fig. 6. (a) Voltage waveform during inrush, (b) RMS value of voltages during inrush, (c) Voltage waveform during fault, (d) RMS value of voltages during fault.

On the other hand, if the transformer is switched $\mathrm{ON}$ in presence of fault within the zone, then both sides of transformer voltages will be unequal $\left(V_{\mathrm{p}} \neq V_{\mathrm{s}}\right)$, which can be clearly visible from Fig. 6(c). The estimated Root Mean Square (RMS) value of these voltages is shown in Fig. 6(d) during faulty transformer energization. If the fault condition is identified, then the algorithm will further check for the type of fault.

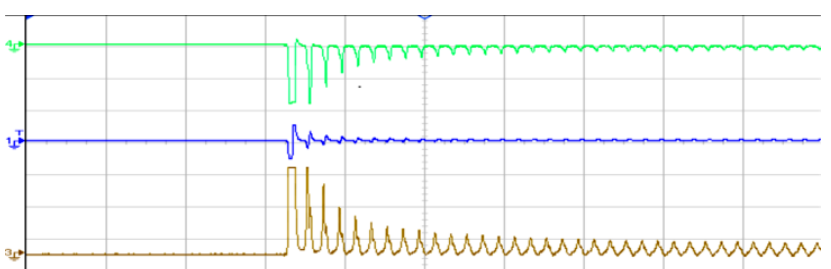

(a) DSO Three Phase Inrush Results

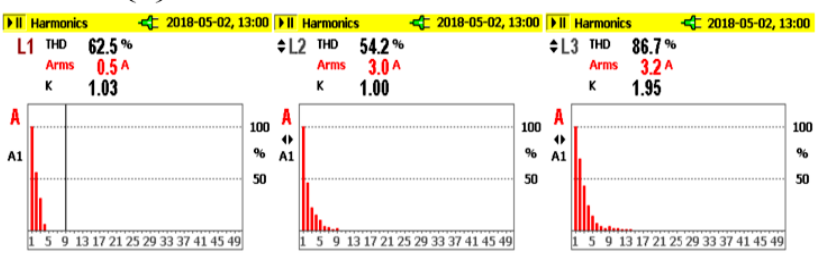

(b) Per Phase Harmonic Content during Inrush

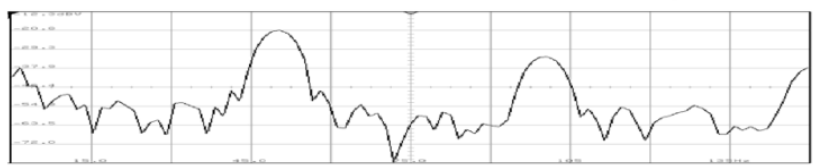

(c) spectrum analysis of Inrush Current

Fig. 7. Inrush condition: (a) Three Phase Inrush Currents waveform, (b) Per Phase Harmonic during inrush, (c) Spectrum analysis during inrush.
Fig. 7(a) shows the recorded waveform of current in DSO at the time of the first energization of the transformer in the laboratory. For cross verification, harmonic analysis and spectrum analysis are carried out, as shown in Fig. 7(b) and $7(c)$, respectively. It is observed that the $2^{\text {nd }}$ harmonic component remains more than 20 percentage compared to the fundamental in every phase during inrush condition, as shown in Fig. 7(b) [1].

\section{B. Internal Fault}

Various single, double and three phase faults are carried out on the transformer winding through $12 \mathrm{ohms}, 18$ amps rheostat in the laboratory environment, as shown in Fig. 8 (a), (b), (c). It is to be noted that for any internal fault whether existing prior to transformer energization or during operation, the voltage equality test $\left(V_{\mathrm{p}}=V_{\mathrm{s}}\right)$ must be performed at the very first stage, as illustrated in Fig. 6(c) and 6(d). Moreover, during fault, the relay continuously compares the differential and restraining power with respect to the set biased slope. As shown in Fig. 8(d), during internal fault condition, the differential power $\left(P_{\mathrm{d}}\right)$ exceeds the restraining power $\left(P_{\mathrm{r}}\right)$ times the set slope and consequently the biased power trajectory falls into the operating zone. Hence, the relay will issue a trip command to the circuit breaker. 

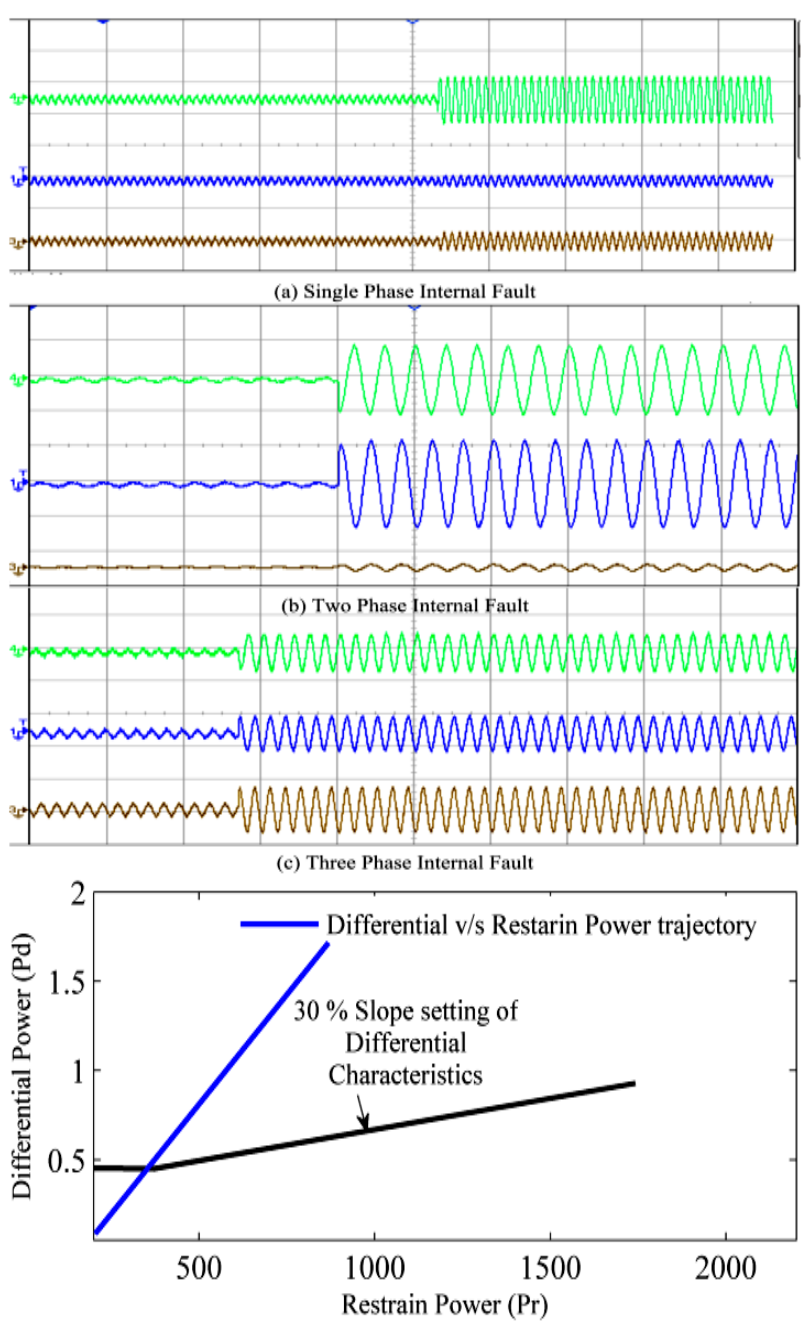

(d) differential V/S Restrain Power Characteristic

Fig. 8. Internal fault conditions.

\section{External Fault or Normal Condition}

In the case of external fault condition, the relay should identify the fault outside the protective zone and remains inoperative. At the instant when fault is applied in the system, the differential power $\left(P_{\mathrm{d}}\right)$ will not exceed the percentage of restraining power $\left(P_{\mathrm{r}}\right)$ and hence the differential characteristic will remain sufficiently below the operating region, as shown in Fig. 10(a). Thus, the proposed scheme will not issue a trip signal.

If we consider the worst case of one CT saturation during external fault condition, we will get distorted waveform from the CT. This distorted waveform will misguide power differential relay logic to issue a trip signal. An adaptive feature has been added in the PDP scheme to tackle the CT saturation during external fault (Fig. 4). An external fault with CT saturation is created on the secondary side of the transformer to check the practicability of the algorithm. A deliberate resistance is inserted in the secondary one of the CTs to put it into saturation state. Figs 9(a, b, c) show the waveform of the CT secondary currents and comparison of voltages from both sides of the transformer to be protected.
As per Equation (2), the level of CT saturation is estimated at $15 \%$. The slope of the biased characteristic will shift up by $15 \%$ as per Eq. (3), hence new slope will be $45 \%$ (Fig. 10(b)), which is calculated in Arithmetic and Logical Unit (ALU) unit of the dedicated processor. The calculated value of $P_{\mathrm{d}}$ remains well below the $45 \%$ of $P_{\mathrm{r}}$, thus adaptive slope prevents false operation of the relay and makes the system more reliable.
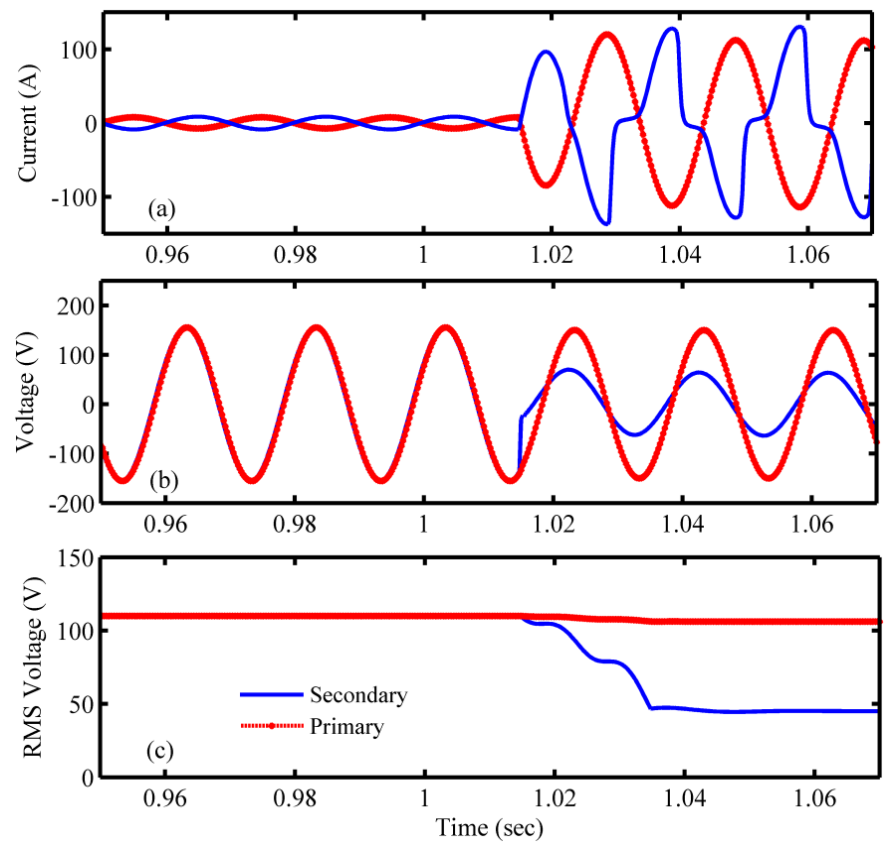

Fig. 9. External condition: (a) Current waveform, (b) Voltage waveform, (c) RMS value of voltages.
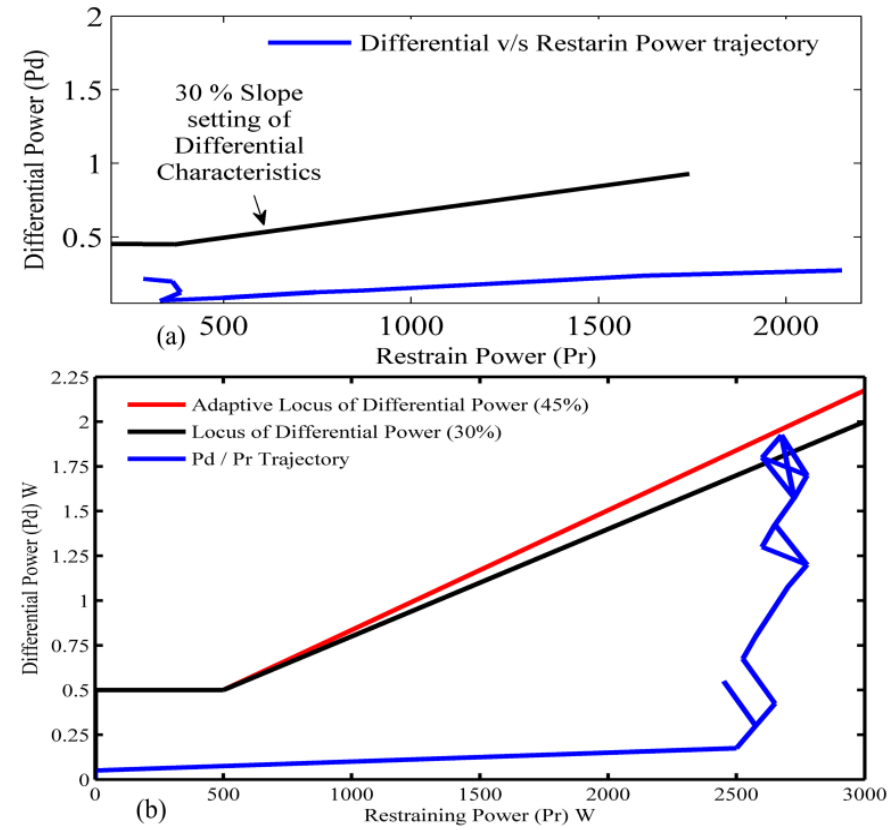

Fig. 10. Differential vs restraining power characteristic during external faultcondition: (a) without CT saturation, (b) with CT saturation. 


\section{Monitoring of Other Transformer Conditions}

The fitness function $\left(F_{\mathrm{f}}\right)$ as described in Eq. (1) is estimated for degradation of various parameter combinations. Fig. 11(a) shows the plot of combination of various parameter variations $\mathrm{v} / \mathrm{s}$ calculated fitness function. The change in temperature, efficiency, and losses as a function of load variation are also estimated and shown in Figs 11(b, c, d), respectively. Table II and Fig. 11(a) show the change in $\mathrm{F}_{f}$ for alteration in magnetic unbalance, winding temperature, harmonic content in current and overloading conditions.
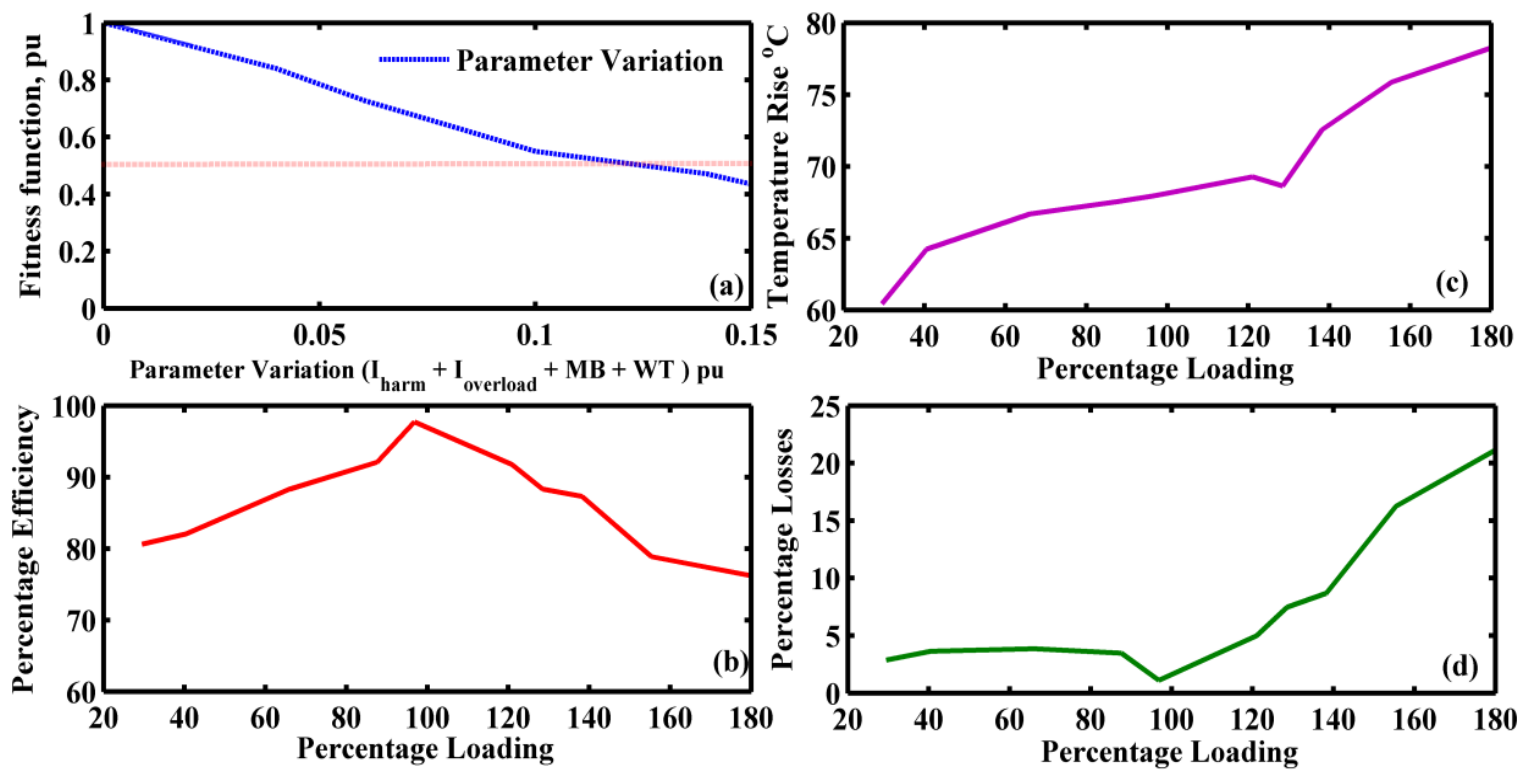

Fig. 11. (a) Parameter variation v/s fitness function, (b) Loading v/s efficiency, (c) Loading v/s temperature and (d) Loading v/s losses.

The health of the transformer is defined here as a grade, based upon the value of fitness function $\left(F_{\mathrm{f}}\right)$. Here we have taken ranges of $F_{\mathrm{f}}$ to reflect its health as $1 \geq F_{\mathrm{f}}>0.9=$ Healthy, $0.9 \geq F_{\mathrm{f}}>0.7=$ Moderate, $0.7 \geq F_{\mathrm{f}}>0.5=$ Poor and for $0.5 \geq F_{\mathrm{f}}=$ Worst. When calculated $F_{\mathrm{f}}$ enters into the range of poor condition, the proposed scheme provides alarm and in the worst case, it will trip the circuit breakers of the transformer.

An example is elaborated here, which sheds more light for estimating fitness function $\left(F_{\mathrm{f}}\right)$.

TABLE II

EXAMPLE FOR ESTIMATING FITNESS FUNCTION $\left(F_{\mathrm{f}}\right)$

\begin{tabular}{|l|c|c|c|c|}
\hline $\begin{array}{l}\text { Sr. } \\
\text { No. }\end{array}$ & $\begin{array}{c}\text { Parameters } \\
\text { considered }\end{array}$ & $\begin{array}{c}\text { Considered } \\
\text { value }(\mathbf{p u})\end{array}$ & $\begin{array}{c}\text { Score } \\
\left(\boldsymbol{S}_{\boldsymbol{i}}\right)\end{array}$ & $\boldsymbol{W} \boldsymbol{f}_{\boldsymbol{i}}$ \\
\hline 1 & MUB & 0.2 & 4 & 3 \\
\hline 2 & WT & 71 & 3 & 1 \\
\hline 3 & Aging Factor & 0.3 & 3 & 4 \\
\hline 4 & Insulation Degradation & 0.4 & 3 & 2 \\
\hline 5 & Current Harmonics & 5 & 4 & 2 \\
\hline 6 & Winding Deformation & 0.0005 & 4 & 3 \\
\hline 7 & Total Heat Generation & 75 & 3 & 1 \\
\hline
\end{tabular}

Here, as per Eq. (1),

$$
\begin{gathered}
F_{\mathrm{f}}=\frac{1}{S_{\max }} \cdot \frac{\sum_{i=1}^{j} S_{i} \cdot W f_{i}}{\sum_{i=1}^{j} W f_{i}}=\frac{1}{4} \cdot \frac{\sum_{i=1}^{7} S_{i} \cdot W f_{i}}{\sum_{i=1}^{7} W f_{i}} \\
=\frac{1}{4} \cdot \frac{(12+3+12+6+8+12+3)}{(3+1+4+2+2+3+1)}=\frac{1}{4} \cdot \frac{56}{16}=0.87
\end{gathered}
$$

Hence, the estimated $F_{\mathrm{f}}$ value of the transformer is 0.87 . Based on this value, the algorithm will make decision for monitoring the transformer.

TABLE III

FITNESS FUNCTION $\left(F_{\mathrm{f}}\right)$ FOR CHANGE IN TRANSFORMER PARAMETER

\begin{tabular}{|c|c|c|}
\hline $\begin{array}{c}\text { Parameters variation in pu } \\
\left(\mathrm{MUB}+\mathrm{WT}+I_{\text {harm }}+I_{\text {overload }}\right)\end{array}$ & $\boldsymbol{F}_{\mathbf{f}}(\mathbf{p u})$ & Grade \\
\hline 0 & 1.00 & Healthy \\
\hline 0.02 & 0.92 & Healthy \\
\hline 0.04 & 0.84 & Moderate \\
\hline 0.06 & 0.73 & Moderate \\
\hline 0.08 & 0.64 & Poor \\
\hline 0.10 & 0.55 & Poor \\
\hline 0.14 & 0.47 & Worst \\
\hline 0.16 & 0.40 & Worst \\
\hline 0.17 & 0.37 & Worst \\
\hline
\end{tabular}




\section{CONCLUSION}

This article presents a real-time monitoring and protection of the power transformer connected in a smart grid. Fitness function $\left(F_{\mathrm{f}}\right)$ is derived from various parameters of the selected transformer. Based on the estimated $\mathrm{F}_{f}$ from the collected real time data for different operating conditions of the transformer, the algorithm provides alarm or a trip command. Also, the realtime monitoring can display the condition of the transformer from healthy to the worst case as shown in Table II. Thus, the proposed online condition monitoring will eliminate unnecessary maintenance required for the transformer, as the scheduled maintenance can be replaced by the necessary maintenance. The scheme developed here is generalized; one can modify the parameters based on the requirements. Moreover, an adaptive power differential protection (APDP) scheme is also presented in combination with condition monitoring. The proposed APDP scheme successfully identifies inrush condition, internal fault and external fault for the transformer to be protected. The developed approach adaptively modifies power differential relay characteristic of the saturation period of the CTs. It is observed that the suggested scheme operates only during internal faults, and remains stable during all external faults, normal load and inrush condition. The proposed combined real-time monitoring and APDP based protective scheme are successfully implemented on a prototype in the laboratory environment on a $15-\mathrm{kVA}$ transformer. The results discussed here justify the viability of the combination of the condition monitoring and APDP scheme. Thus, the suggested scheme can be efficiently employed as a complete protection of any transformer at different voltage levels.

\section{ACKNOWLEDGMENT}

This work is financially supported by the Department of Science and Technology (DST), India, under project reference number EMR/2016/006041.

\section{REFERENCES}

[1] B. Bhalja, R. P. Maheshwari, and N. G. Chothani, Protection and switchgear, Second edition. New Delhi, India: Oxford University Press, 2017.

[2] S. Pai, N. Bansal, K. Desai, A. Doshi, D. Moharkar, and M. Pathare, "Intelligent PLC based transformer cooling control system," International Conference on Nascent Technologies in Engineering (ICNTE), pp. 1-6, 2017. https://doi.org/10.1109/ICNTE.2017.7947926

[3] M. S. Ballal, G. C. Jaiswal, D. R. Tutkane, P. A. Venikar, M. K. Mishra, and H. M. Suryawanshi, "Online condition monitoring system for substation and service transformers," IET Electr. Power Appl., vol. 11, no. 7, pp. 1187-1195, 2017. https://doi.org/10.1049/iet-epa.2016.0842

[4] Y. Cheng, T. Hu, W. Chang, and J. Bi, "Experiments on the multifunctional current sensor for condition detection of transformer bushings," in IEEE Electrical Insulation Conference (EIC), pp. 17-20, 2016. https://doi.org/10.1109/EIC.2016.7548583

[5] IEEE Std C57.140-2017 (Revision of IEEE Std C57.140-2006), IEEE Guide for Evaluation and reconditioning of Liquid Immersed Power Transformers, 27 April 2007. https://doi.org/10.1109/IEEESTD.2007.353650

[6] K. Najdenkoski, G. Rafajlovski, V. Dimcev, "Thermal Aging of Distribution Transformers According to IEEE and IEC Standards", Power Engineering Society General Meeting, IEEE, Tampa, FL, USA, 24-28 June 2007, pp. 1-5. https://doi.org/10.1109/PES.2007.385642
[7] S. Ceferin, G. Janc, Z. Toro, T. Kastelic, and B. Pranikar, "Power transformer monitoring systems for better asset management," CIRED Open Access Proc. J., no. 1, pp. 395-399, 2017. https://doi.org/10.1049/oap-cired.2017.1262

[8] A. E. B. Abu-Elanien, M. M. A. Salama, and M. Ibrahim, "Calculation of a Health Index for Oil-Immersed Transformers Rated Under $69 \mathrm{kV}$ Using Fuzzy Logic," IEEE Trans. Power Deliv., vol. 27, no. 4, pp. 2029-2036, 2012. https://doi.org/10.1109/TPWRD.2012.2205165

[9] A. A. Hossam-Eldin, M. Refaey, and H. Ramadan, "New approach to power transformer asset management and life assessment using fuzzy logic techniques," Nineteenth International Middle East Power Systems Conference (MEPCON), pp. 901-908, 2017. https://doi.org/10.1109/MEPCON.2017.8301287

[10] N. A. Bakar and A. Abu-Siada, "Fuzzy logic approach for transformer remnant life prediction and asset management decision," IEEE Trans. Dielectr. Electr. Insul., vol. 23, no. 5, pp. 3199-3208, 2016. https://doi.org/10.1109/TDEI.2016.7736886

[11] L. Sun, Z. Ma, Y. Shang, Y. Liu, H. Yuan, and G. Wu, "Research on multi-attribute decision-making in condition evaluation for power transformer using fuzzy AHP and modified weighted averaging combination," IET Gener. Transm. Distrib., vol. 10, no. 15, pp. 3855-3864, 2016.https://doi.org/10.1049/iet-gtd.2016.0381

[12] X. Zhang and E. Gockenbach, "Asset-Management of Transformers Based on Condition Monitoring and Standard Diagnosis", IEEE Electr. Insul. Mag., vol. 24, no. 4, pp. 26-40, 2008. https://doi.org/10.1109/MEI.2008.4581371

[13] R. D. Medina, D. X. Morales, M. A. Toledo, and J. B. Cabrera, "Power transformer risk index assessment for an asset management plan," CHILEAN Conference on Electrical, Electronics Engineering, Information and Communication Technologies, pp. 1-7, 2017. https://doi.org/10.1109/CHILECON.2017.8229535

[14] T. Takahashi and T. Okamoto, "Development of asset management support tools for oil-immersed transformer," IEEE Trans. Dielectr. Electr. Insul., vol. 23, no. 3, pp. 1643-1647, 2016. https://doi.org/10.1109/TDEI.2016.005574

[15] R. J. N. de Alencar and U. H. Bezerra, "Power Transformer Differential Protection Through Gradient of the Differential Current," J. Control. Autom. Electr. Syst., vol. 24, no. 1-2, pp. 162-173, 2013. https://doi.org/10.1007/s40313-013-0021-6

[16] E. Ali, A. Helal, H. Desouki, K. Shebl, S. Abdelkader, and O. P. Malik, "Power transformer differential protection using current and voltage ratios," Electr. Power Syst. Res., vol. 154, pp. 140-150, 2018. https://doi.org/10.1016/j.epsr.2017.08.026

[17] F. Namdari, S. Jamali, and P. A. Crossley, "Power differential based wide area protection," Electr. Power Syst. Res., vol. 77, no. 12, pp. 1541-1551, 2007.https://doi.org/10.1016/j.epsr.2006.10.018

[18] A. M. I. Taalab, H. A. Darwish, and E. Ahmed, "Performance of Power Differential Relay with Adaptive Setting for Line Protection," Power Deliv. IEEE Trans., vol. 22, no. 1, pp. 50-58, 2007. https://doi.org/10.1109/TPWRD.2006.877101

[19] L. Sevov, Z. Zhang, I. Voloh, and J. Cardenas, "Differential protection for power transformers with non-standard phase shifts," in 2011 64th Annual Conference for Protective Relay Engineers, pp.301-309, 2011. https://doi.org/10.1109/CPRE.2011.6035631

[20] L. Zhang, W. Cong, T. Xun, and Y. Bai, "A current differential protection criterion based on amplitude and phase difference of fault current," in 2011 International Conference on Advanced Power System Automation and Protection, vol. 1, pp. 346-350, 2011. https://doi.org/10.1109/APAP.2011.6180424

[21] S. Dambhare, S. A. Soman, and M. C. Chandorkar, "Adaptive Current Differential Protection Schemes for Transmission-Line Protection," IEEE Trans. Power Deliv., vol. 24, no. 4, pp. 1832-1841, 2009. https://doi.org/10.1109/TPWRD.2009.2028801

[22] C. Lin, B. Zhang, Y. Yuan, "The Aging Diagnosis of Solid Insulation for Oil- Immersed Power Transformers and Its Remaining Life Prediction" Asia-Pacific Power and Energy Engineering Conference, Chengdu, China, 28-31 March 2010. https://doi.org/10.1109/APPEEC.2010.5449486

[23] U. J. Patel,N. G. Chothani and P. J. Bhatt, "Adaptive quadrilateral distance relaying scheme for fault impedance compensation”, Electrical, Control and Communication Engineering, vol. 14, no. 1, pp. 58-70, 2018. https://doi.org/10.2478/ecce-2018-0007 
[24] N. G. Chothani and B. R. Bhalja, "New Algorithm for current transformer saturation detection and compensation based on derivatives of secondary currents and Newton's backward difference formulae", IET Generation, Transmission \& Distribution, vol. 8, no. 5, pp. 841-850, 2014 https://doi.org/10.1049/iet-gtd.2013.0324

[25] J. Pereira. O. Postolache, P. Girao, H. Ramos, "Minimizing Errors Due to Non-Simultaneous Sampling of Voltage and Current in Digital Power Measurement Systems", Proc. of the 12th IMEKO TC4 Internat. Symp., Electrical Measurements and Instrumentation", Part 1, FEEC Zagreb, Croatia, September 25-27, pp. 307-310, 2002.

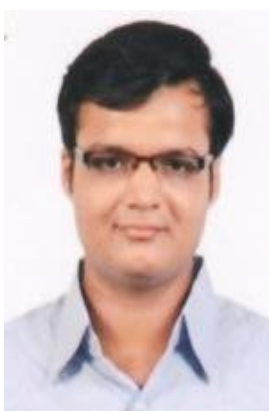

Maulik Raichura is a Research Scholar at the Department of Electrical Engineering, Gujarat Technological University, Gujarat, India. $\mathrm{He}$ received his B.E. degree from A. D. Patel Institute of Technology, New Vallabh Vidhyanagar, Gujarat, India, in 2014 and Master degree in power systems from the Shantilal Shah Engineering College, Bhavnagar, Gujarat, India, in 2016. Currently, he is pursuing his $\mathrm{Ph}$. D. from Gujarat Technological University, Gujarat, India. His area of research is power transformer protection.

He is working as a Junior Research Fellow under DST, SERB grant, DST/EMR/2016/006041 at A. D. Patel Institute of Technology, New Vallabh Vidhyanagar, Gujarat, India.

Postal Address: A. D. Patel Institute of Technology, New Vallabh Vidhyanagar, Vitthal Udyognagar, Anand, Gujarat 388121, India.

E-mail: mbraichura@gmail.com

ORCID iD: https://orcid.org/0000-0001-9244-7835

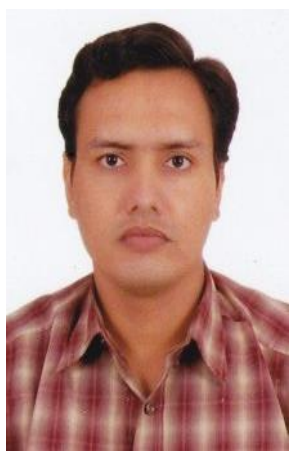

Dr N. G. Chothani received his B. E. degree from Saurashtra University, Rajkot, Gujarat in 2001. He received Master degree in power systems and the $\mathrm{Ph}$. D. degree in electric engineering from the Sardar Patel University, Vallabh Vidhyanagar, Anand, India, in 2004 and 2013, respectively. He has published several research papers in national and international referred journals. His research interests include power system protection, simulation, power system modeling and artificial intelligence.

He is an Associate Professor in the Department of Electrical Engineering, ADIT, New Vallabh Vidhyanagar, India, since 2005. He also worked as a Junior Engineer in state Transmission Company for 2 years. He is Life Member of Indian Society for Technical Education (ISTE) and Life Member of The Institution of Engineers (India).

Postal Address: A. D. Patel Institute of Technology, New Vallabh Vidhyanagar, Vitthal Udyognagar, Anand, Gujarat 388121, India.

E-mail: chothani_nilesh@rediffmail.com

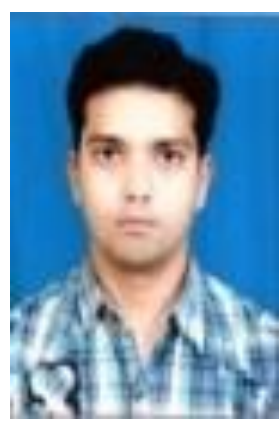

Dr Dharmesh Patel received his B. E. degree from North Gujarat University, Patan, Gujarat, in 1999 and Master degree in power systems from the Sardar Patel University, Vallabh Vidhyanagar, Anand, India in 2002. He has received his Ph. D. degree from Sardar Vallabhbhai National Institute of Technology, Surat, India, in 2019. His field of research is power transformer protection.

$\mathrm{He}$ has been working as an Assistant Professor for 9 years at the Department of Electrical Engineering, Government Engineering College, Bharuch392002, Gujarat, India. He served as a lecturer for 7 years in the state polytechnic college. Also, he worked as a Junior Engineer in State Distribution Company for 1 year.

Postal Address: Electrical Department, Government Engineering College, Bharuch-392002, Gujarat, India.

E-mail: ddeps2005@gmail.com

ORCID iD: https://orcid.org/0000-0003-4862-3963 